\title{
A Relationship Between Goitre Prevalence and Cassava (Manihot esculenta. Crantz) Consumption in Kilifi County, Coast Province of Kenya
}

\author{
Sam Mwachibua Mwadzombo ${ }^{1,}$, , Lenny Mwagandi Chimbevo ${ }^{2}$, Paul Sifuna Oshule ${ }^{1}$, \\ Suliman Essuman ${ }^{3}$, Francis Muchiri Wambura ${ }^{4}$ \\ ${ }^{1}$ Department of Medical Biochemistry, Mount Kenya University, Thika, Kenya \\ ${ }^{2}$ Department of Pure and Applied Sciences, Technical University of Mombasa, Mombasa, Kenya \\ ${ }^{3}$ Department of Medical Microbiology, Mount Kenya University, Thika, Kenya \\ ${ }^{4}$ Department of Health Education and Promotion, Kenya Medical Training College, Nyahururu, Kenya
}

Email address:

mwachibuasam@gmail.com (S. M. Mwadzombo)

${ }^{*}$ Corresponding author

\section{To cite this article:}

Sam Mwachibua Mwadzombo, Lenny Mwagandi Chimbevo, Paul Sifuna Oshule, Suliman Essuman, Francis Muchiri Wambura. A Relationship Between Goitre Prevalence and Cassava (Manihot esculenta. Crantz) Consumption in Kilifi County, Coast Province of Kenya. Science Journal of Public Health. Vol. 7, No. 6, 2019, pp. 206-213. doi: 10.11648/j.sjph.20190706.15

Received: May 21, 2019; Accepted: November 8, 2019; Published: November 19, 2019

\begin{abstract}
In tropical areas, absence or poor growth of potatoes and grains makes cassava a common food. However, presence of goitrogenic compounds make cassava unfit for human consumption hindering its contribution to curb food security. The study is aimed at providing evidence based relationship between goitre prevalence and cassava consumption in Kilifi County. A longitudinal retrospective quantitative study design was conducted in six randomly selected hospitals (Wananchi Hospital, Swiss Cottage Hospital, Watamu Hospital, Malindi District Hospital, Mariakani Sub-County Hospital, Kilifi County Referral Hospital). Secondary data from Hospital records were used to identify goitre patients where questionnaires were administered and respondent's response scored. Statistical Package for Social Scientists (SPSS) was used to summarize data and determine correlations. A total of 673503 patients attended hospitals, $232(0.034 \%)$ had goitre, 99 (42.67\%) were reached; 7 (7.07\%) and 92 (92.93\%) were none consumers and consumers of cassava respectively. Raw cassava consumption is a high risk factor (62\%) compared to cooked (21.7\%), milled (7.6\%), roasted (5.4\%) and fried (3.3\%) forms of cassava. Adult women (52.2\%), pregnant women (32.6\%) and children of both sex (10.9\%) were more susceptible than adult males (4.3\%). 89.20\% patients consumed both leaves and roots, $6.4 \%$ roots and $5.4 \%$ leaves. Flesh, central part and both flesh and central part of root consumed by $5 \%, 7 \%$ and $87 \%$ patients respectively. Four species of cassava were grown and consumed as follows 79.30\% Chibandameno (Manihot esculenta mantenha), 10.8\% Kaleso (Manihot esculenta paraibu) $6.5 \%$ Original (Manihot esculenta amanolinha) and 3.4\% Mgrikacha (Manihot esculenta parmada). Cassava is consumed due to culture $(13 \%)$, medicine $(5.4 \%)$, food $(18.4 \%)$, sexual drive booster $(9.8 \%)$ and making other foods $(53.4 \%)$. It can be concluded cassava consumption may induce goitre. The study recommends chemical analysis of goitrogenic compounds in blood, urine, various parts and methods of preparation of different species of cassava.
\end{abstract}

Keywords: Cassava Induced Goitre, Consumption, Prevalence

\section{Introduction}

Goitre is the most common clinical feature of thyroid pathology [1]. In most cases, it reflects impaired thyroid hormone (TH) manufacture due to deficiency or defective absorption of dietary iodine by thyroid gland [2]. Ingestion of goitrogenic substances, including cassava [3-6], may lead to defective $\mathrm{TH}$ manufacturing resulting to compensatory mechanism kicks leading to increment of blood thyroid stimulating hormone (TSH), causing hyperplasia and hypertrophy of thyroid cells, thus an increase in size of the 
thyroid gland $[6-8,1]$. The disorder can be in the form of euthyroid, hyperthyroidism orhypothyroidism states [2]. The condition is commonly in females as compares to males [9], with highest rate of new cases during adolescent, due to abrupt increased physiologic demand for T4 and T3 [8]. Goitres are usually painless may cause compression neurological and endocrinological symptoms, enlarged neck mass, vascular compression on neck and supra-thoracic area and mimic cancer of thyroid [8, 10, 11, 1] making it very hard to diagnose on the basis of clinical manifestation only.

Cassava (Manihot esculenta) is an indigenous plant along tropics that is widely grown and used as a major source of food $[6,12]$. Its nutritious value has play very important roles in the diets of many countries specifically in African, as major sources of low cost carbohydrates [13]. Cassava in most of the time is not grown as a cash crop but rather as a subsistence crop [14, 15], can be milled into flour where maize is added during milling process making the flour nutritious thus a source of staple food in many parts of the world [6]. It grows very well in poor soils, resist drought and resist weeds, diseases and pests making it a great significance and effective plant in terms of provision of food during unfavorable conditions [15].

Despite all of the above factors, cassava contains potential goitrogenic chemicals that may potentiate iodine deficiency disorders, which includes goitre, cretinism among many others [3, 16-19, 5]. Metabolic and epidemiological studies indicate that many factors are responsible for causing endemic goitre [4, 20-22]. Risk factors for relating the association between goitre and cassava consumption have been studied in other countries [23, 24]. Raw cassava contains cyanogenic compounds, which inhibits the process

\section{Materials and Methods}

\subsection{Study Area}

The study was conducted in Kilifi county situated in coastal region of Kenya whose geographical coordinates are: Latitude; $3^{\circ} 40^{\prime} 0.001$ " S, Longitudinal: $39^{\circ} 45^{\prime} 0.00^{\prime}$ E. It borders Mombasa County to South East, Kwale County to the South West, Lamu County to the North West, Taita-taveta County to the West and Indian Ocean to the East. It has a total area of $12,245.90 \mathrm{~km}^{2}$. The county has a population of $1,109,735$ (male $-48 \%$ and female $-52 \%$ ), according to the 2009 National census [37].

\subsection{Study and Sampling Design and Sample Size}

The study used a quantitative approach to determine the variables under study made possible by use of a five-point likert scale [38]. A quantitative approach, which was longitudinal nature and retrospective, was used as the study design. The study population included people who were diagnosed with goitre attending selected hospitals, residence of Kilifi County and consume cassava. All goitrogenic and cassava consumers and residence of Kilifi County were included in the study while none goitrogenic, none residence and goitrogenic none cassava consumers living in Kilifi County were excluded from the study. of organification of iodide and coupling reaction and uptake of iodide and interferes with the activity of thyroid peroxidase (TPO) [25]. Gender also plays a role although the mechanism is not known [26]. Processing of cassava before consumption [27], part of cassava [28, 29] and types of cassava consumed $[30,31]$ may further contribute to goitre in cassava consumption population. Further, environmental conditions such as drought play a role in determining cyanogenic glycosides content of the tuberous root [32].

One third of the world's populations is at risk of goitre with total goitre prevalence (TGP) estimated at 15.8\%, 4.7\% and $28 \%$ in Amidst, America and Africa respectively [33]. However, there has been variation in the world prevalence of goitre in children aged 6-12 years [34]. In Africa the prevalence was estimated at $22.3 \%$ in southern Sudan [35], $39 \%$ in Kenya, with the rates of $27.7 \%$ and $12 \%$ for invisible and visible goitre respectively [33]. Although mechanisms of how cassava can cause goitre has also been studied $[36,11]$, only a few emphasized the relationship between cassava consumption and prevalence of goitre. Kilifi County being a region whose residents consumes cassava and a good number of people have visible goitre. Further, the situation is complicated by the cases of invisible goitre. There is no study, which has been conducted in Kilifi County for the prevalence of goitre in cassava consuming population. Hence there is need to determine whether its prevalence is caused by one of the major staple food, which is cassava in this county. The study intends to show how frequent one can consume cassava and get goitre in Kilifi County in relation to the mode of preparation, subtypes of cassava, age, gender, the exact part of cassava consumed and their mechanisms.

Six hospitals were randomly selected from all the hospitals in Kilifi County. The selected hospitals included; Kilifi County Referral Hospital, Mariakani Sub-County Hospital, Watamu Hospital, Malindi District Hospital, Wananchi Hospital and Swiss Cottage Hospital. A total of 385 patients were selected randomly from the six randomly selected hospitals, from all the patients diagnosed of goitre with replacement.

\subsection{Data Collection, Analysis and Management}

In the first phase, secondary data from the hospitals records was used to determine the number of patients who were residence diagnosed with goitre. Thereafter questionnaire was used to collect primary data. A pilot study was conducted in two different hospitals not included in the study and results were computed to determine and confirm the reliability of the questionnaire. The questionnaire was administered in the six randomly selected hospitals (for the patients who were in the hospital) and at home (for the patients who were diagnosed at hospital but were at home) to collect the primary data. Before administration of the questionnaire, the participants signed an informed consent. The questionnaire was also re-administered to the same respondents for the second time after two days or four days depending on the available of the respondent. The respondent's responses were scored and the results for the $1^{\text {st }}$ and $2^{\text {nd }}$ administration guided by Marcer and Kneer as described 
[39]. Quantitative data collected was presented inform of graphs, charts and table. Descriptive statistics was used to summarize the data by used means and standard deviation whereas inferential statistic was used to determine correlations, relationships between different variable through the use of statistical package from social scientists (SPSS).

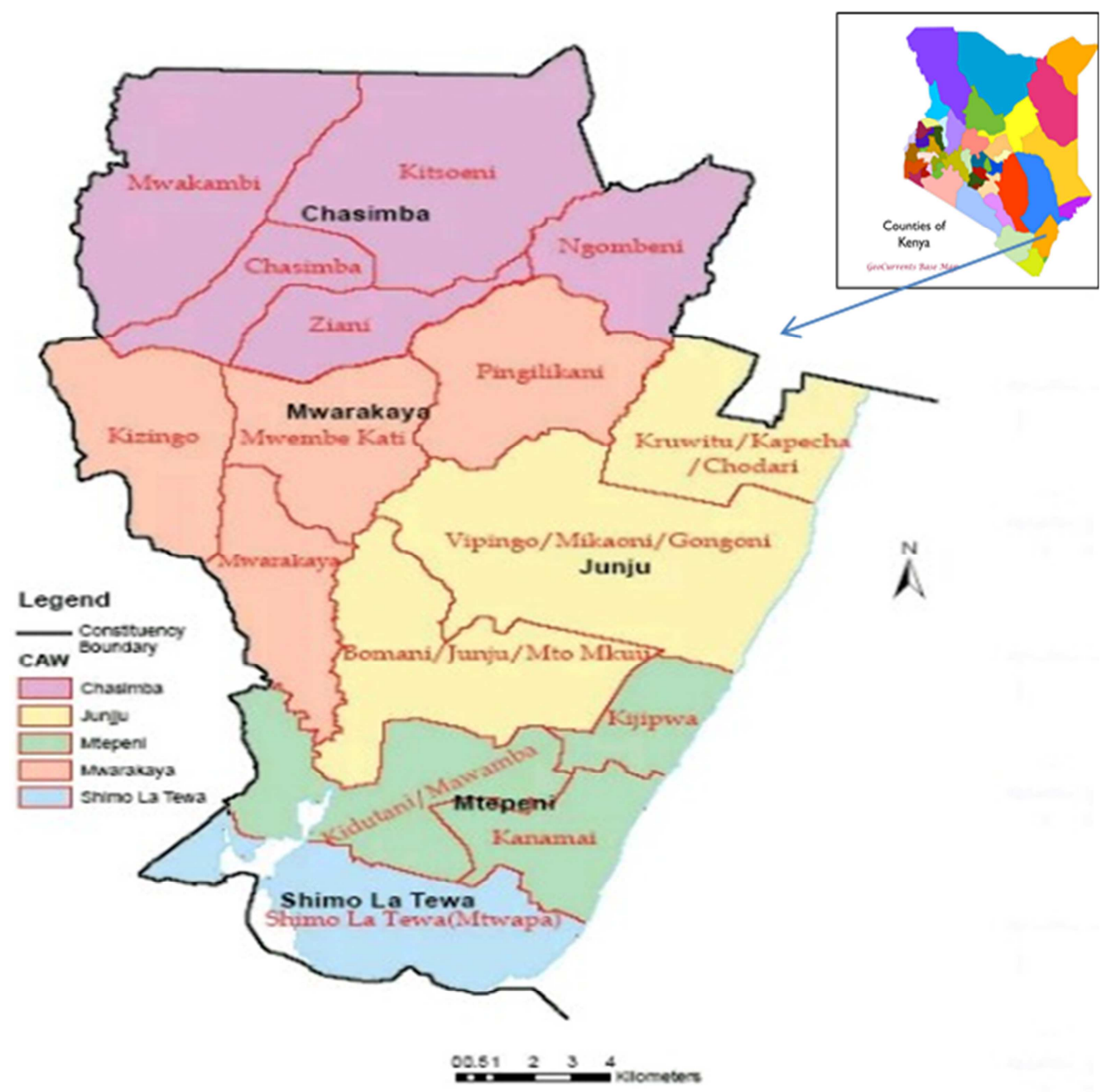

Figure 1. A map of Kilifi County showing the areas and sites involved in the study.

\subsection{Ethical Consideration}

The participants involved in the study read, understood and signed informed consent letter. The subjects were given codes for the purpose of monitoring in the future. Permission to conduct the study was granted by Mount Kenya University (MKU) Institutional Research and Ethics Committee (IREC), National Commission for Science, Technology and Innovation (NACOSTI) and Health Management Team (CHMT) under the County Health Director (CHD) in Kilifi County.

\section{Results}

The expected sample size was 385 patients but the number of respondents obtained was 99 , which were given questionnaire and successfully returned for analysis. The total number of patients who visited the selected hospitals and diagnosed with goitre, who were to be traced and do or don't consume cassava in Kilifi County in a span of one year is presented in Table 1. From the study it can be revealed that Kilifi county referral hospital had the highest number of patients' attendances (247270) with the highest number of goitre patients (84), followed by Watamu hospital (148363) with 52 goitrogenic patients. However, all of the goitrogenic patients in Watamu Hospital (23) and Kilifi County Referral Hospital (31) were cassava consumers. None Goitrogenic cassava consumer patients were found in Malindi district hospital (2), Mariakani sub-County Hospital (2), Swiss Cottage Hospital (1) and Wananchi Hospital (2). The goitrogenic cassava consuming patient were in other hospitals visited were 5 (Wananchi Hospital), 8 (Swiss Cottage Hospital), 11 (Mariakani SubCounty Hospital) and 14 (Malindi District Hospital). Watamu Hospital and Malindi District Hospital had the highest percentage rate of the respondent of $44 \%$ each while Wananchi Hospital had the lowest percentage rate of the respondent (31\%). A total of 673,503 patients visited the selected hospital under study but only $0.034 \%$ (232) of the patients were diagnosed of goitre. Further, $42.67 \%$ (99) of the goitrogenic patients were reached; with $92.93 \%$ (92) consuming cassava while $7.07 \%$ (7) were none cassava consumers. 
Table 1. Response rate among sampled respondents.

\begin{tabular}{lllllll}
\hline Hospital visited & $\begin{array}{l}\text { Yearly Patients } \\
\text { attendance }\end{array}$ & $\begin{array}{l}\text { Patients diagnosed } \\
\text { with goitre }\end{array}$ & $\begin{array}{l}\text { Patients } \\
\text { reached }\end{array}$ & $\begin{array}{l}\text { Non cassava } \\
\text { consumers patients }\end{array}$ & $\begin{array}{l}\text { Cassava consumers } \\
\text { patients }\end{array}$ & $\begin{array}{l}\text { Percentage rate of } \\
\text { the respondents }\end{array}$ \\
\hline Wananchi Hospital & 24,727 & 16 & 7 & 2 & 5 & \\
Swiss Cottage Hospital & 20,631 & 19 & 9 & 1 & 8 & $31 \%$ \\
Watamu Hospital & 148,363 & 52 & 23 & 0 & 23 & $42 \%$ \\
Malindi District Hospital & 123,605 & 32 & 16 & 2 & 14 & $44 \%$ \\
Mariakani Sub-County Hospital & 108,908 & 29 & 13 & 2 & 11 & $44 \%$ \\
Kilifi County Referral Hospital & 247270 & 84 & 31 & 0 & 31 & $38 \%$ \\
Total & 673,503 & 232 & 99 & 7 & 92 & $37 \%$ \\
\hline
\end{tabular}

In attempt to establish risk factors contributing to goitre in cassava consuming population, the study found out that consumption of raw and unprocessed cassava, gender, age, pregnancy, part of cassava consumed, part of the root and type of cassava consumed were among the risk factors contributing to goitre in Kilifi County. The relationship between cassava consumption and goitre is presented in Table 2.

Table 2. Cassava consumption as a risk factor of goitre in Kilifi County.

\begin{tabular}{lll}
\hline $\begin{array}{l}\text { Form of cassava } \\
\text { consumed }\end{array}$ & $\begin{array}{l}\text { Frequency of } \\
\text { patients }\end{array}$ & $\begin{array}{l}\text { Percentage of } \\
\text { patients }\end{array}$ \\
\hline Raw cassava & 57 & $62 \%$ \\
Milled cassava & 7 & $7.6 \%$ \\
Fried cassava & 3 & $3.3 \%$ \\
Roasted cassava & 5 & $5.4 \%$ \\
Cooked cassava & 20 & $21.7 \%$ \\
TOTAL & 92 & $100 \%$ \\
\hline
\end{tabular}

The data obtained from this study indicates that there is a strong relationship between consumption of raw cassava and goitre as depicted by the highest frequency $57(62 \%)$ of patients with goitre preferred consuming raw cassava than any other mode of preparation. The methods of preparation of the cassava before consumption such as milling, frying, roasting and cooking reduced the chances of contracting goitre. This is supported by the findings that a small number of goitrogenic patients processed their cassava through milling (7.6\%), frying (3.3\%), roasting (5.4\%) and Cooking $(21.7 \%)$. The results strongly suggest that the best processing method of cassava is frying, followed by roasting, milling and cooking in that order.

The role of gender, age and pregnancy as risk factors of goitre in Kilifi County is presented in Table 3.

Table 3. Gender, age and pregnancy as risk factors of goitre in Kilifi County.

\begin{tabular}{lll}
\hline Patient's variables & Frequency of goitre & Percentage of goitre \\
\hline Adult male & 4 & 4.3 \\
Adult female & 48 & 52.2 \\
Children & 10 & 10.9 \\
Pregnant women & 30 & 32.6 \\
TOTAL & 92 & 100 \\
\hline
\end{tabular}

It can be established from the study that adult women $(52.2 \%)$ and children of both sex $(10.9 \%)$ are more susceptible to goitre than adult males (4.3\%). Further, the study indicates that pregnancy is a risk factor as $30(32.6 \%)$ patients were expectant women. From the results of this study, it is evident that female overall are at a higher risk of getting goitre $(52.2 \%$ for adult females and $32.2 \%$ for pregnant women), therefore there is a strong correlation between goitre and the female gender. The part of cassava consumed may also play a role in the development of goitre. The relationship between goitre and part of cassava consumed in Kilifi County is presented in Figure 2.

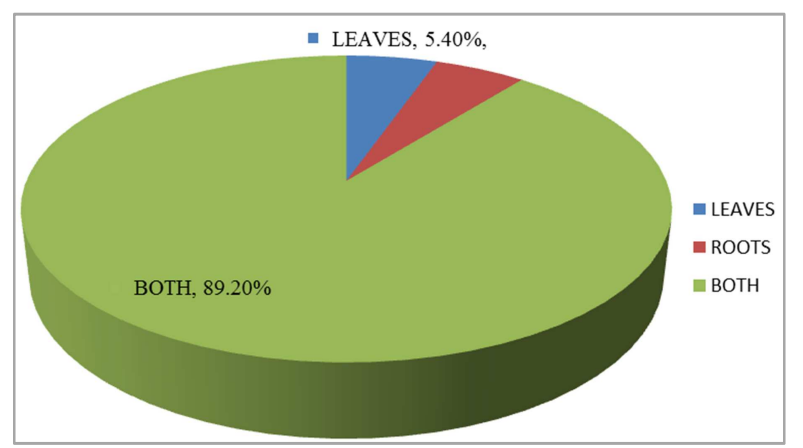

Figure 2. Different parts of cassava consumed as risk factors of goitre in Kilifi County.

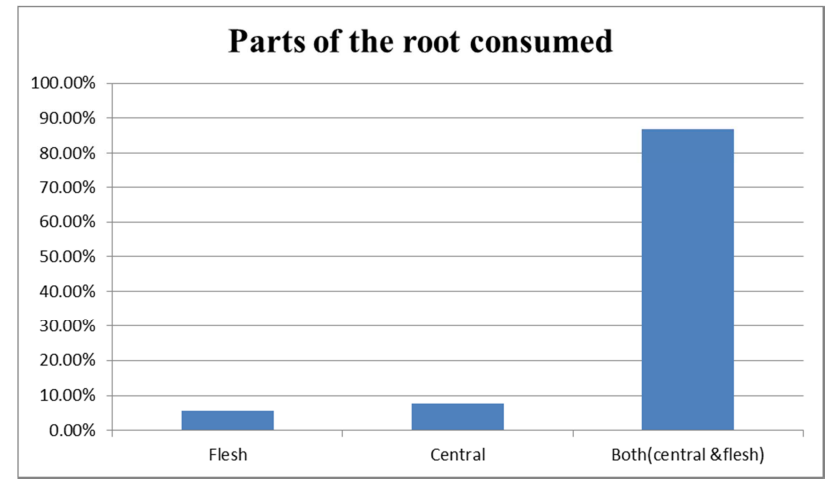

Figure 3. Different parts of the root consumed as risk factors of goitre in Kilifi County.

Majority of the patients $(89.20 \%)$ diagnosed with goitre in Kilifi County were found to consume both the leaves and roots while only $5.40 \%$ of patients consumed either leaves or roots. Therefore, it can be deduced from the study that there is a notable relationship between the part of the root consumed and goitre. Since the root in most cases is the one consumed, attempt was made to find out the part of the root consumed in relation to the number of patient with goitre in cassava consuming population in Kilifi county. The different parts of the root consumed as risk factors of goitre in Kilifi County are presented in Figure 3. The study shows 
most patients diagnosed with goitre $(87 \%)$ are due to consumption of both the fleshy and the central part $8 \%$ consumes the central part of the root and 5\%consume the fleshy part of cassava root. This supports the findings that individuals who consume the central part of the cassava root are more likely to get goitre than those consuming the fleshy part of cassava.

The study further established that there is four types of cassava consumed which is a risk factor, which contributed to goitre in Kilifi County (Table 4). These sub type of cassava are consumed for various reasons on basis in Kilifi County (Table 5). The results of the study support that Chibandameno has high frequency in causing goitre with a frequency of 73 (79.3\%). 3 (3.4\%), Mgrikacha11 (10.8\%), Kaleso and 7 (6.5\%) Original.

Table 4. Number of respondents and their preferred type of cassava they consume.

\begin{tabular}{llll}
\hline Botanical name & Local name & Frequency & Percentage \\
\hline $\begin{array}{l}\text { Manihot esculenta } \\
\begin{array}{l}\text { amanolinha } \\
\text { Manihot esculenta }\end{array}\end{array}$ & Original & 7 & 6.5 \\
$\begin{array}{l}\text { mantenha } \\
\text { Manihot esculenta } \\
\text { paraibu }\end{array}$ & Kaleso & 11 & 79.3 \\
$\begin{array}{l}\text { Manihot esculenta } \\
\text { parmada }\end{array}$ & Mgrikacha & 3 & 10.8 \\
TOTAL & & 92 & 3.4 \\
\hline
\end{tabular}

The study also established that $100 \%$ of the total respondents agreed that most people in Kilifi County consume cassava on daily basis and the results are presented in Table 5. The reasons for daily consumption of cassava in Kilifi County include $12(13 \%)$ cultural value, $5(5.4 \%)$ therapeutic value, 17 (18.4\%) unfavorable environment, 9 $(9.8 \%)$ sexual drive booster and $49(53.4 \%)$ make other variety of foods e.g. Bread, Chapati, Cakes and Ugali.

Table 5. Reasons for daily consumption of cassava by population in Kilifi County.

\begin{tabular}{lll}
\hline Responses & Frequency & Percentage (\%) \\
\hline Culture & 12 & 13 \\
Medicine & 5 & 5.4 \\
Only food & 17 & 18.4 \\
Sexual drive booster & 9 & 9.8 \\
Make other foods & 49 & 53.4 \\
TOTAL & 92 & 100 \\
\hline
\end{tabular}

In the estimation of prevalence of goitre in cassava consuming population, the total population 1,109,735 people of Kilifi County (KBS, 2009) was used. Within one year, a total of 673,503 patients attended the selected six (6) out of the fourteen (14) hospitals in Kilifi County. Therefore, a total of 1,571,507 patients $(14 \times 673503) / 6)$ attended hospitals in Kilifi County within a period of one year. Further, 232 patients out of 673,503 patients from the six (6) selected hospitals were diagnosed with goitre. Therefore, the entire Kilifi Count with what about 1,571,507 people had about 541 $(232 \times 1,571,507 / 673503)$ goitrogenic patients. From the 99 goitre patients, the study found 92 cassava consumers and 7 non cassava consumers. The population of about 541 goitre patients, $38(541 \times 7) / 99)$ patients were none cassava consumers while $503(541-38)$ patients were cassava consumers. Therefore, for every 100 goitre patients, 92 $(100 * 503) / 541)$ patients are cassava induced. Therefore, in every 100 cases of goitre in Kilifi County Hospitals, 92 cases are due to cassava consumption. In estimation of prevalence of goitre caused by cassava consumption in the county 673503 patients attended six selected hospitals were the sample population, out this 232 had goitre, the study managed to trace 99 of this patients. Out of the 99,7 patients were non cassava consumers hence $16(232 \times 7 / 99)$ was the total of non cassava consumers giving 216 goitre patients due to cassava consumption. Therefore, prevalence of goitre due to cassava consumption was $0.032 \%(216 / 673503 \times 100)$.

\section{Discussion}

The present work is carried out to investigate the relationship between prevalence of goitre and cassava consumption in Kilifi County. Further, there are few studies that have been performed to ascertain aetiology of goitre such as iodine, TH (T3, T4) and TSH; enzymes (AST and ALT), electrolytes $(\mathrm{Na}+$ and $\mathrm{K}+$ ) thiocyanate, and iodine [1, 40] and their roles especially in cassava consuming communities. This study serves as a base line survey for further work to investigate the interaction of these various aetiological factors in the development of goitre. Thiocyanate, cyanide and hydrocyanate have been implicated in goitre development in several studies [41-43].

Food is the main source of cyanide ions in the body, although inhalation through the lungs or absorption through the mucus membrane can also occur. The Cruciferous vegetables which include cassava, lima beans, millet, and sweet potatoes among other [44, 45] are consumed by most house holds in Kilifi County. Owing to erotic rain pattern in Kilifi County cassava is one of the major staple food. The amount of hydrogen-cyanide consumption is in part, a function of the method of processing of cassava products and disposal of processing water. The number of uses to which cassava is put into is also an important determinant of intake levels. The fact that cassava appears in many of their diets (in different varieties and forms), is recognized as an important factor capable of raising the overall daily toxicant intake. They contain cyanoglucosides, which when hydrolyzed liberate the goitrogenic, hydrogen cyanide. Cassava consumption has been found to contribute to iodine deficiency; hence goitre may be more prevalent among cassava consuming population.

Consumption of raw cassava has been shown to be one of the risk factors contributing to goitre among cassava consuming population in Kilifi County. Raw cassava is more potent in causing goitre than milled, fried, roasted or cooked cassava. Raw cassava has increased levels of hydrogen cyanide. However, goitrogenics or antithyroid potentials of cassava don't depend only on cyanogenic compounds found in raw form but also in the processed form. Measures which 
are commonly used to reduce the goitrogenic potency are: boiling, washing, soaking, cooking etc. [46, 47, 25]. Hydrogen cyanide works in two ways to affect the thyroid hormone synthesis, one it inhibits the uptake of iodine and two it interferes with the activity of thyroid peroxidase (TPO), through inhibition of the process of organification of iodide and coupling reaction [48].

Cyanogenic compounds in cassava reduce upon preparation [25]. This forms the basis as to why the number of patients with goitre who consumed processed cassava was small. Nonprocessed cassava contained excess goitrogenic this is why the number of cassava induced goitre was high. The study has also established that women and children are more prone to goitre in cassava consuming population. From the cultures of the Mijikenda who occupy most of but not all parts of Kilifi County, women are the ones to harvest and prepare the cassava, which makes them prone to excessive consumption of both the raw, and the prepared cassava. On the other hand, children tend to spend much time with their mothers, which increase their chances from exposure to the goitrogenic. Further more children contain a lot of endogenous thiosulphate which readily acts with cyanide to form thiocyanate which inhibits the synthesis of thyroid hormones [38].

The study established that $89.2 \%$ of the patients who were diagnosed with goitre were frequent consumers of cassava leaves and its roots and $5.4 \%$ of the goitre patients consumed either the leaves alone or the roots. This suggested that the amount of goitrogenics in leaves and roots are equal, which contradict Balagopalan and co-workers [28] who stated that the amount of goitrogenics is highest are leaves, followed by the peel then the fleshy part. The study also established that Chibandameno consumption predisposes to goitre than the other subtypes found in Kilifi County. This conclusion was made after the study found out that most patients who had goitre in Kilifi County preferred this subtype of cassava. This subtype, the residents report to be non - bitter, which contradict some literatures that state that the bitter the cassava the higher the amount of goitrogenics. Therefore, it was expected that Chibandameno should be bitter.

Cassava induced goitre is common in Kilifi County because a large number of the population consume cassava on daily basis. There are many reasons as to why many families consume cassava everyday in Kilifi County. One being, many families can't afford other foods making them go for the easily affordable ones, which include cassava. Poor climate in Kilifi County, which does not support growing of other foods, also contributes to the highest dependence on cassava. The evolving art of making different types of foods e.g. Cakes, Ugali, Chapati, etc., from cassava in Kilifi County has also contributed to the daily consumption of cassava. This leads to slow accumulation of hydrogen cyanide, which reacts with thiosulphate to form thiocyanate that inhibits the formation thyroid hormones leading to goitre.

\section{Conclusion}

The study was conducted to determine the prevalence of goitre in cassava consuming population in Kilifi County. The study identified consumption of raw and none processed cassava, gender, age, pregnancy, part of cassava consumed, part of the root consumed and the type of cassava consumed contribute to the occurrence of goitre in the cassava consumers. Government involvement was found to be the most favored method of trying to reduce and prevent the occurrence of cassava induced goitre. Most of the responds also acknowledge that religious organizations and other learning institutions should be creating awareness on cassava consumption at large to help reduce the high number of cassava induced goitre.

\section{Recommendations}

Based on the findings of the study, provision of conventional medicine by the government to the residence of Kilifi County targeting the population consuming cassava as a herbal medicine is recommended. This will reduce cassava consumers hence reducing the number of goitre patients. The County government may implement programs that provide the necessary requirement to promote other crops to be grown in Kilifi County even in drought seasons. Provision of water for irrigation, fertilizers and education on the proper methods of farming to reduce the dependency on cassava may reduce cassavainduced goitre. The religious and learning institutes should also take a leading role in imparting knowledge to the community of Kilifi County on the risks of cassava consumption that can lead to goitre. They should educate the people of Kilifi to discard some of the retrogressive cultural beliefs on cassava. By doing so the incidence of cassava induced goitre is expected to diminish with time. Suggestions for further research include; chemicals compounds, which contribute to goitre in cassava in respective to the subtypes and the part of cassava, consumed, level of awareness and stigma on goitre patients in Kilifi County. The study recommends conducting further studies based on the prevalence of cassava-induced goitre obtained. Chemical analysis of consumed parts (roots and leaves) of cassava and their preparation methods to be conducted to ascertain the presence of goitrogenic compounds. Last but no the least a follow up on the goitre patient be conducted to establish the relationship between the goitrogenic chemicals obtained from the analysis and their role in development of goitre in the cassava consuming community in Kilifi county.

\section{Acknowledgements}

We would like to express our special thanks to the community in Kilifi County during period of study. Mount Kenya University through Sam Mwachibua Mwadzombo an undergraduate student undertaking Bachelor of Medicine and Bachelor of Surgery (MB. ChB) degree is indebted for funding and supporting this research study. 


\section{References}

[1] Felig. P. Frohman H. and Lawrence A. Goitre, Endocrinology and Metabolism. McGraw Hill Professional. 2001.

[2] Madukosiri CH. and Ikale E. Iodine content in diet and urine of people in Imiringi and Otuasega communities in Ogbia LGA Bayelsa. Electronic Journal of Environment, Agriculture and Food Chemistry. 2011: 10 (5), 2216-2221.

[3] Nartey F. Biosynthesis of cyanogenic glucosides in cassava (Manihot spp.), Chronic cassava toxicity: proceedings of an interdisciplinary workshop, London, England. 1973; 73-87.

[4] Delange FM. Velden V. and Ermans A. Evidence of an antithyroid action of cassava in man and in animals, Chronic cassava toxicity of proceedings of an interdisciplinary workshop in London, England. 1973: 147-151.

[5] Butler GW. Reay PF. and Tapper BA. Physiological and genetic aspects of cyanogenesis in cassava and other plants. Chronic cassava toxicity of proceedings of an interdisciplinary workshop, London, England. 1973: 65-71.

[6] Onyenwoke CA. and Simonyan KJ. Cassava post-harvest processing and storage in Nigeria: A review, African Journal of Agricultural Research. 2014: 9 (53), 3853-3863.

[7] WHO, UNICEF, ICCIDD. Assessment of iodine deficiency disorders and monitoring their elimination. A guide for Programme Managers, $2^{\text {nd }}$ ed. World Health Organization, Geneva. 2001: 740 .

[8] Middlesworth L. and Jones SL. Endocrinology, African journal of traditional, complementary and alternative medicine. 2006: 87-99.

[9] Madukosiri CH. and Adoga GI. Elemental status of pregnant and lactating women in Bassa LGA of Plateau State, Nigeria. Pakistan Journal of Nutrition. 2011: 10 (5) 401404.

[10] Schott M. Thyrotropin receptor autoantibodies in Graves's disease, $A$ review on the role of anti-TSHR autoantibodies in Graves's disease, and methods for detecting these antibodies. 2005: 16: 243.

[11] Stassi G, and De Maria R, Autoimmune thyroid disease: new models of cell death in autoimmunity. Nat Rev Immunol, $A$ review on autoimmune thyroid disorders, particularly the pathogenesis of Hashimoto and other thyroiditis. 2002: 2: 195.

[12] OECD. Consensus Document on Compositional Considerations for New Varieties of CASSAVA (Manihot esculenta Crantz): Key Food and Feed Nutrients, Antinutrients, Toxicants and Allergens. Organization for Economic Co-operation and Development (OECD). 2009.

[13] Montagnac JA. Davis CR. and Tanumihardjo SA. Nutritional Value of Cassava for Use as a Staple Food and Recent Advances for Improvement. Institute of Food Technologists: Comprehensive Reviews in Food Science and Food Safety. 2009: 8: 181-194.

[14] Nweke FI. Poulson R. and Strauss J. Cassava production trends in Africa. In Tropical Root Crops in a Developing Economy. Proceedings of the 9th Symposium of the International Society for Tropical Root Crops; 20th-26th October, 1994, Accra, Ghana. 311-321.
[15] Chukwuji CO. Inoni OE. and Ike PC. Determinants of technical efficiency in gari processing in Delta state Nigeria. Journal of Central European Agriculture. 2007: 8 (3): 327336.

[16] Siritunga D. and Sayre R. Engineering cyanogen synthesis and turnover in cassava, The Ohio state university Columbus OH 43210. 2004.

[17] Cock JH. Cyanide toxicity in relation to the cassava research program of CIAT in Colombia, Chronic cassava toxicity in proceedings of an interdisciplinary workshop in London, England. 1973: 37-48.

[18] Nestel B. Current utilization and future potential for cassava. In Chronic cassava toxicity: proceedings of an interdisciplinary workshop, London, England. 1973: 11-26.

[19] Haque MR. and Bradbury JH. Simple Method for Determination of Thiocyanate in Urine. Clinical Chemistry. 1999: 45 (9) 1459-1464.

[20] Ermans AM. Role of a dietary goitrogen in the etiology of endemic goiter on Idjw Island. Am J Clin Nutr. 1971. 24: 1354-1360.

[21] Ermans AM. Vis H. Stanbury JB. Endemic cretinism in Idjwi Island (Kivu Lake, Republic of Congo). J Clin Endocrinol Metab. 1972: 34: 1059-1066.

[22] Iteke FB, Ermans AM. Nutritional Factors Involved in the Goitrogenic Action of Cassava. Ottawa: International Development Research Centre. 1982.

[23] Mezgebu Y. Prevalence and severity of iodine deficiency disorder among children 6-12 years of age in Shebe Senbo District, Jimma Zone, Southwest Ethiopia. Ethiop J Health Sci. 2012: 22 (3): 199-201.

[24] Tebeb HN. Goitre problems in Ethiopia. Am. J. Clin. Nutr. 1993: 57 (2): 315S-6S.

[25] Ogbera AO. Fasanmade O. Adediran O. Pattern of thyroid disorders in the South Western region of Nigeria. Ethn Dis. 2007; 17: 327-30.

[26] Bradbury JH. (2006). Simple wetting method to reduce cyanogens content of cassava flour. J. Food Compos. Anal. 19: 388-393.

[27] Taylor N. Chavarriaga P. Raemakers K. Siritunga D. and Peng Z. "Development and Application of Transgenic technologies in Cassava", Plant Molecular Biology. 2004: 56: 671-688.

[28] Balagopalan C. Padmaja G. Nanda SK. Moorthy SN. Cassava in Food, Feed and Industry; CRC Press: Boca Raton, FL, USA. 1988.

[29] Nweke IF. Spencer DSC. and Lyman KJ. The cassava transformation. Africa best-kept secret. Michigan State University Press, East Lansing. 2002.

[30] Wobeto C. Corrêa AD. de Abreu CMP. dos Santos CD. and Pereira HV. "Antinutrients in the Cassava (Manhihot esculenta Crantz) Leaf Powder at Three Ages of the Plant", Ciênc. Technol. Alilment. Campinas. 2007: 1: 108-112.

[31] Ketiku, AO. and Oyenuga, VA. Preliminary report on the carbohydrate constituents of cassava roots and yam tubers. Niger. J. Sci. 1970: 4 (1): 25-30. 
[32] Bruun G. The cyanogenic character of cassava (Manihot esculenta). 1973.

[33] Alvarez-Pedrerol M. Guxens M. Mendez M. Canet Y. Martorell R. Espada M. and Sunyer J. Iodine levels and thyroid hormones in healthy pregnant women and birth weight of their offspring. European Journal of Endocrinology. 2009: 160 (3): 423-429.

[34] Andersson M. De Benoist BD. Bruno K. Darnton-Hill B. Ian Y. Delange S. François M. Iodine deficiency in Europe: a continuing public health problem M. Andersson (Ed.) Iodine Deficiency Diseases Europe. 2007.

[35] Andersson M. Takkouche B. Egli I. and Benoist BD. The WHO Global Database on iodine deficiency disorders: the importance of monitoring iodine nutrition. Scandinavian Journal of Nutrition. 2003: 47 (4): 162-166.

[36] Hetzel B. The Story of Iodine Deficiency: An International Challenge in Nutrition. New York, USA: Oxford University Press. 1989.

[37] KNBS-SID. Exploring Kenya's inequality, pulling apart or pooling together. Kenya National Bureau of Statistics (KNBS) and the Society for International Development (SID). 2013.

[38] Berhanu N. Wolde-Michael K. and Bezabih M. Endemic goiter in school children in Southwestern Ethiopia. Ethiop $\mathrm{J}$ Health Dev. 2004: 18.

[39] Kulwa M. Kamuzora K. and Leo G. Urinary iodine concentration and availability of iodated salt in school children in goiter endemic district of Tanzania. East Afr Med J. 2006: 83 .

[40] Madukosiri CH. A pilot study on the aetiology of goitre in Bayelsa state, Nigeria. American journal of food and nutrition. 2011: doi: 10.5251/ajfn.2011.1.4.193.200.
[41] Osuntokun BO. Cassava diet, Chronic cyanide intoxication and neuropathy in Nigerian Africans. World rev Nutr. Diet. 1981: 36: 141-173.

[42] Altamir BS. Soto-Blanco B. Guerra JL. Edna TK. Imura RI. Silvana LG. Does prolonged exposure to thiocyanide toxicity promote hepatotoxicity and nephrotoxicity? Toxicology. 2002: 174: 87-95.

[43] Tulsawani RK. Debnath M. Pant SC. Kumar OM. Prakash AO. Viyayaraghavan R. Bhattacharya. Effects of sub-acute oral cyanide administration in rats: Protective efficacy of alpha-ketoglutarate and sodium thiosulfate. ChemicoBiological Interactions. 2005: 156, 1: 12.

[44] Fowke JH. Fahey JW. Stephenson KK. and Hebert. R. Using Isothiocyanate excretion as a biological marker of Brassic vegetable consumption in epidemiological studies.: Evaluating the sources of variability. Public Health Nutriton. 2001: 4 (3): 837-46.

[45] Montgomery RD. Cyanogens. In: Liener IE, (Ed). Toxic constituents of plant foodstuffs. Academic Press, New York. 1980: 143-160.

[46] Cardoso AP. Ernesto M. Cliff J. Egan SV. Bradbury JH. Cyanogenic potential of cassava flour: field trial in Mozambique of a simple kit. Intl. J. Food Sci. Nutr. 1998: 49: 93-99.

[47] Cardoso AP. Ernesto M. Nicala D. Combination of cassava flour cyanide and urinary thiocyanide measurements of school children in Mozambique. International Journal of Food Science and Nutrition. 2004: 55: 183-190.

[48] Dawit-Shawel SH. Carl K. Lachat G. Martin E. Kimanya E. and Patrick K. Post-production Losses in Iodine Concentration of Salt Hamper the Control of Iodine Deficiency Disorders: A Case Study in Northern Ethiopia. J. Health. Popul. Nutr. 2010: 28 (3), 238-244. 